\title{
Spigelian-cryptorchidism syndrome: a case report and discussion of the basic elements in a possibly new congenital syndrome
}

\author{
C. Rushfeldt • G. Oltmanns $\cdot$ B. Vonen
}

Accepted: 21 July 2010/Published online: 3 August 2010

(C) The Author(s) 2010. This article is published with open access at Springerlink.com

\begin{abstract}
Pediatric cases of Spigelian hernias are rare. Only a few reports on this condition, in combination with ipsilateral cryptorchidism and testis in the hernia sac, have been published. We report on Spigelian hernia in a 3-weekold boy containing both the ipsilateral testis, without a gubernaculum and an incarcerated loop of the small intestine. It has been suggested that the combination of Spigelian hernia and ipsilateral cryptorchidism is part of a new syndrome. We discuss whether the lack of a gubernaculum and an inguinal canal reported in other similar cases may be additional elements of this new syndrome. We present a comprehensive overview of pediatric patients with Spigelian-cryptorchidism syndrome reported in the English language literature. In $75 \%$ of male infants with Spigelian hernia, there is an associated ipsilateral cryptorchidism, and in $87 \%$ of these patients, the testis is found inside the hernia sac. Thus, the surgeon dealing with a congenital Spigelian hernia should look for an undescended testis and be prepared to find it in the hernia sac.
\end{abstract}

Keywords Spigelian hernia · Cryptorchidism - Testis . Gubernaculum · Inguinal canal

C. Rushfeldt $(\bowtie) \cdot B$. Vonen

Department of Gastroenterological Surgery,

University Hospital of North Norway, 9038 Troms $\varnothing$, Norway

e-mail: ch-rushf@online.no

G. Oltmanns

Department of Radiology,

University Hospital of North Norway, Troms $\varnothing$, Norway

\section{Introduction}

Spigelian hernia is a rare condition, constituting $0.12 \%$ of all ventral hernias [1]. It is most common in adults, with only 24 pediatric cases reported up until 2006 [2]. The anatomical basis of Spigelian hernia is weakness in the Spigelian hernia belt arising from a transversus abdominis aponeurosis between the lateral edge of the rectus sheath and the semilunar line. Most Spigelian hernias occur cranially and laterally to the epigastric inferior vessels, but with occasional medial and caudal location they are named "low spigelian hernias" [3]. Whereas adult Spigelian hernias are considered to be acquired because of trauma or increased intra-abdominal pressure, pediatric cases are suspected to be congenital [2,4].

Among male infants with Spigelian hernias, $75 \%$ presented are associated with cryptorchidism [2]. Raveenthiran [5] suggested that a defect in the Spigelian fascia, combined with ipsilateral cryptorchidism, may be part of a new syndrome. We report here on a 3-week-old child with a concomitant incarceration of the small intestine and testis in Spigelian hernia sac. We suggest that the additional lack of a gubernaculum observed in this patient, as well as the lack of an inguinal canal observed by others in similar cases, may be considered as two additional and closely connected elements of this new syndrome.

\section{Case report}

A 16-day-old full-term boy was admitted to hospital with dehydration after he had refused breastfeeding. Clinical and laboratory examination did not reveal any underlying specific disease, and he was discharged after 2 days. No information on the content of the scrotum was recorded in 


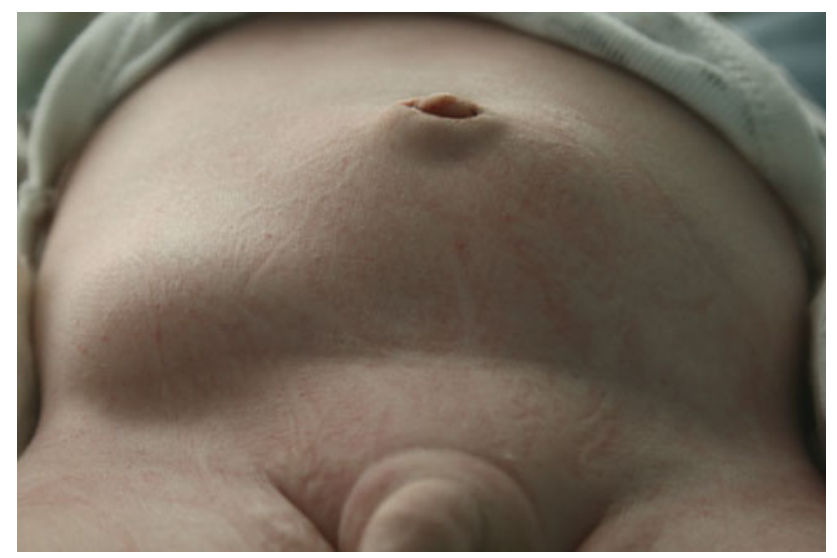

Fig. 1 The Spigelian hernia appearing as a bulge on the lower, ventral abdomen

the EPJ notes from this admission. 4 days later, he was readmitted with pain and the appearance of a bulge in the right, lower part of the abdominal wall (Fig. 1) and no testis in the right scrotum. The abdominal wall swelling was not reducible after sedation. An ultrasound revealed a hernia sac located between the $\mathrm{m}$. obliquus externus and $\mathrm{m}$. obliquus internus, penetrating through a $7 \mathrm{~mm}$ wide hernia opening. The sac contained a normal-sized right testis and a loop of small intestine with weak peristaltic movements. A normal X-ray did not show any sign of ileus.

The hernia was repaired the same day under general anesthesia. Following a horizontal, small skin incision, an elongated hernia sac directed in a craniolateral direction was dissected from the position under the obliquus externus muscle with its port close to the lateral edge of the rectus muscle (Fig. 2a). The sac was opened and contained a normal-sized right testis, with no gubernacular cord attached to the epididymis in the lower pole of the testis, and the mesorchium of the testis was connected directly to the wall of the hernia sac.

In addition, a loop of the small intestine with compromised circulation (Fig. 2b) was incarcerated inside the hernia sac. The small intestine was recovered and returned to the abdomen, aided by a small incision in the hernia port. The testis, with a sufficient long spermatic cord, was dissected from the hernia sac and tunneled subcutaneously into a subdartos pouch. The hernia sac was then resected, and the opening was closed around the cord. No exploration for an inguinal canal was performed, and no complications occurred.

\section{Discussion}

A successful descent of a testis is preceded by the development of an inguinal canal, which depends on the
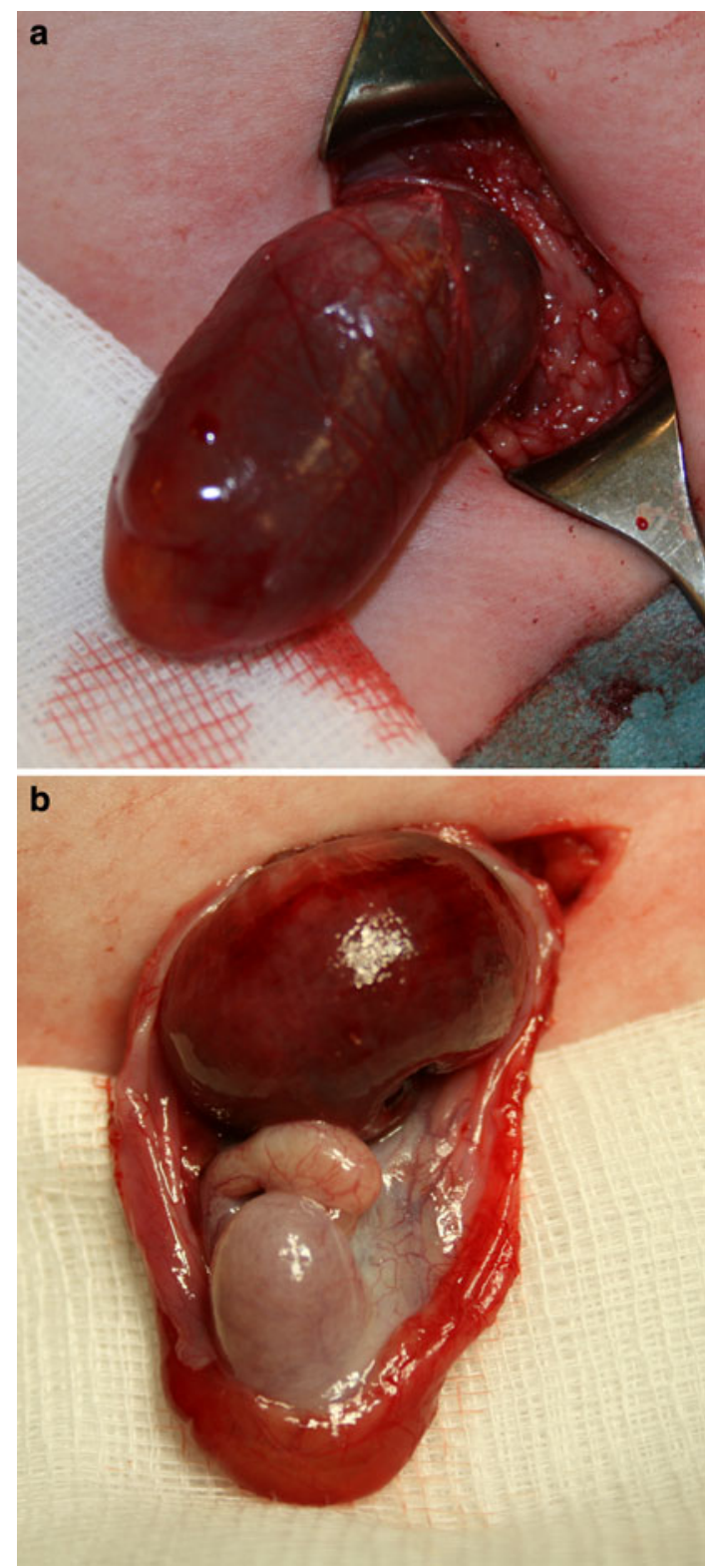

Fig. 2 a The Spigelian hernia sac after dissection, b the Spigelian hernia sac containing a normal testis without gubernaculum and a loop of small intestine with compromised circulation

formation of the gubernaculum ligaments during the seventh gestational week descending from the inferior poles of the testes down through the abdominal wall at the site of the future inguinal canals. The processus vaginalis, an evagination of the peritoneum, then develops along the gubernaculum and herniates through the abdominal wall forming the inguinal canal. In the third month, thickening and shortening of the gubernaculum both pulls the testis down to the deep inguinal ring and enlarges the inguinal canal to make space for the last phase of the testicular descent. Between the seventh and the ninth months, the transinguinal descent takes place under the influence of 
androgens bringing the testes into the scrotum due to a second gubernacular shortening, which is aided by an increase in abdominal pressure [6-8].

Most Spigelian hernias associated with a cryptorchidism are recognized at birth or shortly thereafter (Table 1), indicating a congenital condition. In our patient, no gubernaculum was identified during the operation. In 8 out of the 15 patients in Table 1, the authors have reported no sign of gubernaculum, though this question has not been addressed in the corresponding reports for the other patients. However, we question whether the gubernaculum may have been missing in these cases as well since no gubernaculum-related adhesions in the hernia sac were reported during surgery.

We did not look for an inguinal canal during the acute operation of our patient. Other surgeons have reported a concomitant ipsilateral lack of both the gubernaculum and inguinal canal in 6 patients with 7 hernias and the lack of an inguinal canal, with no information on the gubernaculum in 2 additional patients. It is evident from the embryology that the gubernaculum is a prerequisite for the development of an inguinal canal [9-11]. We therefore assume that patients without a gubernaculum also lack the inguinal canal on the same side, even in cases in which no preoperative exploration for an inguinal canal was performed.

In our patient as well as the others listed in Table 1, the spermatic cord was of sufficient length to bring the testes into the scrotum through a subcutaneous tunnel in the subdartos pouch. Still, the testes lacking gubernacula have descended all of the intra-abdominal distance without the aid of a gubernaculum. However, it is known that the transabdominal movement of the testes is largely a relative movement which results from growth of the cranial part of the abdomen away from the caudal part [6], therefore not depending on the shortening of a gubernaculum.

A syndrome is defined as a group of signs and symptoms that collectively characterize or indicate a particular disease or abnormal condition. Raveenthiran [5] suggested that the co-existence of Spigelian hernia and an ipsilateral

Table 1 Fifteen patients with a total of 18 Spigelian hernias combined with ipsilateral cryptorchidism, published in the English language literature

\begin{tabular}{|c|c|c|c|c|c|}
\hline $\begin{array}{l}\text { Author } \\
\text { [reference] }\end{array}$ & $\begin{array}{l}\text { Age at } \\
\text { diagnosis } \\
\text { (months) }\end{array}$ & Content of hernia sac & $\begin{array}{l}\text { Presence of } \\
\text { inguinal canal }\end{array}$ & $\begin{array}{l}\text { Presence of } \\
\text { gubernaculum }\end{array}$ & Additional anomalies \\
\hline Gravier et al. [12] & 9 & Left testis & ND & ND & Right indirect inguinal hernia \\
\hline Pul and Pul [13] & 18 & Small intestine & ND & ND & No \\
\hline \multirow[t]{2}{*}{ Silberstein et al. [14] } & 0 & Left testis, bowel & Not identified & ND & $\begin{array}{l}\text { Abdominal wall weakness } \\
\text { right side }\end{array}$ \\
\hline & 0 & Right testis, bowel & Not identified & Not identified & No \\
\hline Ostlie and Zerella [15] & 0 & Right testis & Not identified & Not identified & No \\
\hline \multirow[t]{2}{*}{ Al-Salem [4] } & 3 & $\begin{array}{l}\text { Left testis } \\
\text { Sigmoid colon }\end{array}$ & ND & Not identified & No \\
\hline & 0 & Left testis & ND & ND & Multiple anomalias \\
\hline \multirow[t]{2}{*}{ Levy et al. [16] } & 1 & $\begin{array}{l}\text { Right sac: right testis, } \\
\text { small bowel } \\
\text { Left sac: left testis }\end{array}$ & ND & ND & No \\
\hline & 1 & $\begin{array}{l}\text { Left testis, small } \\
\text { intestine }\end{array}$ & ND & ND & No \\
\hline Raveenthiran [5] & 1 & $\begin{array}{l}\text { Right testis (on the outer } \\
\text { aspect of the sac), } \\
\text { bowel }\end{array}$ & Not identified & ND & $\begin{array}{l}\text { Imperforate anus, left inguinal } \\
\text { hernia, umbilical hernia }\end{array}$ \\
\hline \multirow{4}{*}{$\begin{array}{l}\text { Durham and Ricketts } \\
\text { [2] }\end{array}$} & 8 & Left testis & Not identified & Not identified* & No \\
\hline & 13 & $\begin{array}{l}\text { Right sac: right testis } \\
\text { Left sac: left testis }\end{array}$ & Not identified both sides & Not identified* & No \\
\hline & 14 & $\begin{array}{l}\text { Right sac: right testis } \\
\text { Left sac: left testis }\end{array}$ & Not identified both sides & $\begin{array}{l}\text { Not identified both } \\
\text { sides* }\end{array}$ & No \\
\hline & 2 & Right sac: no content & $\begin{array}{l}\text { Not identified on right } \\
\text { side }\end{array}$ & Not identified* & $\begin{array}{l}\text { Right testis intra-abdominal, } \\
\text { left testis in inguinal canal }\end{array}$ \\
\hline $\begin{array}{l}\text { Rushfeldt ( } 2010, \\
\text { present paper) }\end{array}$ & 1 & $\begin{array}{l}\text { Right testis, small } \\
\text { intestine }\end{array}$ & ND & Not identified & No \\
\hline
\end{tabular}

$N D$ no data

* Personal communication 
undescended testis probably forms a new syndrome. According to his hypothesis, the first step is a testicular maldescent of unknown origin. Then, the ectopic testis "drags down a processus vaginalis" that forms a potential hernia sac. This sac opens up with increased intraabdominal pressure, thus converting it into Spigelian hernia. In the absence of a gubernaculum and inguinal canal, this hernia may serve as an "emergency exit" for the testis. When evaluating his theory, it should be remarked that in the patient referred to in this paper, with multiple anomalias, the testis was found outside the hernia sac, thereby mimicking a testis on the outside of a processus vaginalis, such as in the case of a normal testicular descent through the inguinal canal. In all the other patients in Table 1 , in which the testes were found to be associated with the hernia sac, they were located inside the sac. As a result, this finding does not support the Raveenthiran's theory of an ectopic processus vaginalis. In addition, his hypothesis that the testis drags down a processus vaginalis analogous to a normal scrotal descent is not in accordance with general embryologic knowledge $[6,7,9,10]$.

Our theory is that the first step in the Spigelian-cryptorchidism syndrome is a failure in the development of a gubernaculum. As a consequence, the inguinal canal will not develop and the testis will not be able to descend from their intra-abdominal position to the scrotum. These three interconnected elements have only been described in relation to congenital Spigelian hernias, and we do not know how they are connected with the ipsilateral defect in the Spigelian fascia. Is there an unknown mechanism leading to these simultaneous defects, or may the arrested testis induce a sort of rescue canal through a weak area in the abdominal wall in the absence of an inguinal canal?

It has been reported that $75 \%$ of male infants with Spigelian hernia present an ipsilateral cryptorchidism [2] and it has been shown (Table 1) that the testis is found inside the hernia sac in $87 \%$ of these patients. Because of this, a surgeon dealing with Spigelian hernia should look for an undescended testis, and expect it to be in the hernia sac if it is not detected in the scrotum or the inguinal canal. Furthermore, he should be prepared to perform an orchiopexia via a subcutaneous route since an inguinal canal may very well not be found. Another surgical implication is that Spigelian hernia containing a testis should be excluded during the ultrasound investigation of a congenital cryptorchidism when a testis is not found along the pathway of inguinal descent.

We conclude that a cryptorchidism, combined with the finding of the ipsilateral testis in Spigelian hernia sac, is probably a new congenital syndrome which is distinct from an ordinary cryptorchidism in addition to being distinct from other pediatric Spigelian hernias. We hypothesize that "the Spigelian-cryptorchidism syndrome" consists of the following four congenital, ipsilateral elements: a defect in the Spigelian fascia, a hernia sac containing the testis, the absence of gubernaculum and the absence of an inguinal canal. Future surgical explorations and descriptions of these rare cases may add more evidence to this theory. Also, the exact mechanism behind this syndrome, as well as the probable connection between the defect in the Spigelian fascia and gubernaculum-associated defects, remain to be investigated. The pediatric surgeon should be aware of these associated anomalies when dealing with Spigelian hernias and/or cryptorchidism in male infants.

Open Access This article is distributed under the terms of the Creative Commons Attribution Noncommercial License which permits any noncommercial use, distribution, and reproduction in any medium, provided the original author(s) and source are credited.

\section{References}

1. Mittal T, Kumar V, Khullar R, Sharma A, Soni V, Baijal M, Chowbey PK (2008) Diagnosis and management of Spigelian hernia: a review of literature and our experience. J Minim Access Surg 4:95-98

2. Durham MM, Ricketts RR (2006) Congenital spigelian hernias and cryptorchidism. J Pediatr Surg 41:1814-1817

3. Spangen L (1984) Spigelian hernia. Surg Clin North Am 64:351-366

4. Al-Salem AH (2000) Congenital Spigelian hernia and cryptorchidism: cause or coincidence? Pediatr Surg Int 16:433-436

5. Raveenthiran V (2005) Congenital Spigelian hernia with cryptorchidism: probably a new syndrome. Hernia 9:378-380

6. Moore KL, Persaud TVN (2003) The urogenital system. In: The developing human. Clinically oriented embryology, 7th edn. Saunders, Philadelphia (PA), pp 322-324

7. Larsen WJ (2001) Development of the urogenital system. In: Sherman LS, Potter SS, Scott WJ (eds) Human embryology, 3rd edn. Churchill Livingstone, Philadelphia (PA), pp 288-292

8. Carlson BM (2004) Urogenital system. In: Human embryology and developmental biology, 3rd edn. Mosby, Philadelphia (PA), pp 417-419

9. Niikura H, Okamoto S, Nagase S, Takano T, Murakami G, Tatsumi H, Yaegashi N (2008) Fetal development of the human gubernaculums with special reference to the fascia and muscles around it. Clin Anat 21:547-557

10. Biasutto SN, Repetto E, Aliendo MM, Borghino VN (2009) Inguinal canal development: the muscular wall and the role of the gubernaculum. Clin Anat 22:614-618

11. Hutson JM, Hasthorpe S (2005) Testicular descent and cryptorchidism: the state of the art in 2004. J Pediatr Surg 40:297-302

12. Gravier L, Bernstein D, RuBane F (1978) Lateral ventral (spigelian) hernias in infants and children. Surgery 83:288-290

13. Pul N, Pul M (1994) Spigelian hernia in children: report of two cases and review of the literature. Yonsei Med J 35:101-104

14. Silberstein PA, Kern IB, Shi ECP (1996) Congenital Spigelian hernia with cryptorchidism. J Pediatr Surg 31:1208-1210

15. Ostlie DJ, Zerella JT (1998) Undescended testicle associated with Spigelian hernia. J Pediatr Surg 33:1426-1428

16. Levy G, Nagar H, Blachar A, Ben-Sira L, Kessler A (2003) Preoperative sonographic diagnosis of incarcerated neonatal Spigelian hernia containing the testis. Pediatr Radiol 33:407-409 